\title{
Os desafios da supervisão pedagógica no ensino no Tocantins: uma reflexão do
}

\section{documento curricular}

The challenges of pedagogical supervision in teaching in Tocantins: a reflection on the curriculum

\section{document}

Los desafíos de la supervisión pedagógica en la enseñanza en Tocantins: una reflexión sobre el documento curricular

\section{Resumo}

O presente estudo tem como propósito compreender a atuação do Supervisor Pedagógico no processo educativo e prática docente para o desenvolvimento do ensino e aprendizagem dos estudantes na Educação Básica, no contexto da implementação do Documento Curricular do Tocantins (DCT). A reflexão sobre suas competências poderá contribuir para o entendimento de sua identidade e relevância social, política e administrativa de seu papel na escola quanto ao apoio à prática dos professores, no tocante ao ensino e à aprendizagem. Trata-se de pesquisa bibliográfica, documental, exploratória, com uso do método dedutivo e uma abordagem qualitativa. O DCT para a Educação Infantil e o Ensino Fundamental, foi criado para aprimorar e orientar o processo de ensino e aprendizagem, nas redes de ensino do território tocantinense. De forma colaborativa, os 139 municípios se organizaram para atender ao disposto no Art. 76 da Resolução CEE-TO/CP Nº 024/2019, e à Estratégia 3.1 da Meta 3, do Plano Estadual de Educação, Lei $\mathrm{n}^{\circ}$ 2.977, de 8 de julho de 2015. Os resultados da investigação apontaram que a implementação do DCT veio assegurar a finalidade dos currículos escolares, considerando as histórias dos estudantes, as circunstâncias e as realidades locais, como também os aspectos, voltados ao planejamento e o monitoramento; a comunicação e o engajamento; os processos formativos; o apoio técnico e o fortalecimento da gestão pedagógica. Isso denota uma nova visão das práticas do Supervisor Pedagógico no espaço escolar, a partir de uma intervenção conceituada na ação coletiva.

Palavras-chave: Supervisão escolar; Prática docente; Documento curricular do Tocantins.

\begin{abstract}
This study aims to understand the role of the Pedagogical Supervisor in the educational process and teaching practice for the development of teaching and learning of students in Basic Education, in the context of implementing the Tocantins Curriculum Document (DCT). The reflection on their competences can contribute to the understanding of their identity and social, political and administrative relevance of their role in the school in terms of supporting teachers' practice, with regard to teaching and learning. It is a bibliographic, documentary, exploratory research, using the deductive method and a qualitative approach. The DCT for Early Childhood Education and Elementary Education was created to improve and guide the teaching and learning process in teaching networks in the Tocantins territory. In a collaborative way, the 139 municipalities organized themselves to comply with the provisions of Article 76 of Resolution CEE-TO/CP No. 024/2019, and Strategy 3.1 of Goal 3, of the State Education Plan, Law No. 2.977, of 8th of July 2015. The results of the investigation indicated that the implementation of the DCT came to ensure the purpose of the school curricula, considering the students' histories, circumstances and local realities, as well as aspects, focused on planning and monitoring; communication and engagement; formative processes; technical support and strengthening of pedagogical management. This denotes a new vision of the Pedagogical Supervisor's practices in the school space, based on a conceptualized intervention in collective action.
\end{abstract}

Keywords: School supervision; Teaching practice; Tocantins curriculum document. 


\begin{abstract}
Resumen
Este estudio tiene como objetivo comprender el papel del Supervisor Pedagógico en el proceso educativo y la práctica docente para el desarrollo de la enseñanza y el aprendizaje de los estudiantes de Educación Básica, en el contexto de la implementación del Documento Curricular de Tocantins (DCT). La reflexión sobre sus competencias puede contribuir a la comprensión de su identidad y la relevancia social, política y administrativa de su papel en la escuela en términos de apoyo a la práctica docente, en lo que respecta a la enseñanza y el aprendizaje. Es una investigación bibliográfica, documental, exploratoria, utilizando el método deductivo y un enfoque cualitativo. El DCT de Educación Infantil y Educación Primaria fue creado para mejorar y orientar el proceso de enseñanza y aprendizaje en las redes de enseñanza en el territorio de Tocantins. De manera colaborativa, los 139 municipios se organizaron para cumplir con lo dispuesto en el artículo 76 de la Resolución CEE-TO / CP No. 024/2019, y la Estrategia 3.1 de la Meta 3, del Plan Estatal de Educación, Ley No. 2.977, de 8 de julio de 2015. Los resultados de la investigación indicaron que la implementación del DCT vino a asegurar el propósito de los planes de estudio escolares, considerando las historias, circunstancias y realidades locales de los estudiantes, así como aspectos, enfocados a la planificación y seguimiento; comunicación y compromiso; procesos formativos; apoyo técnico y fortalecimiento de la gestión pedagógica. Esto denota una nueva visión de las prácticas del Supervisor Pedagógico en el espacio escolar, basada en una intervención conceptualizada en la acción colectiva.
\end{abstract}

Palabras clave: Supervisión escolar; Práctica docente; Documento curricular de Tocantins.

\title{
1. Introdução
}

O presente estudo tem como propósito compreender a atuação do Supervisor Pedagógico na prática e formação docente para o desenvolvimento do ensino e aprendizagem dos estudantes na Educação Básica, no contexto da implementação do Documento Curricular do Tocantins (DCT).

A Educação Básica abrange a Educação Infantil, Ensino Fundamental e Ensino Médio, sendo um direito de todo cidadão brasileiro e dever do estado conforme estabelecido no artigo 205 da Constituição Federal de 1988:

A educação, direito de todos e dever do Estado e da família, será promovida e incentivada com a colaboração da sociedade, visando ao pleno desenvolvimento da pessoa, seu preparo para o exercício da cidadania e sua qualificação para o trabalho (Brasil, 1988).

Além da Constituição Federal (Brasil, 1988) e da Lei de Diretrizes e Bases da Educação Nacional (LDB) (Brasil, 1996), tem surgido a busca constante por uma educação de qualidade, podendo-se citar o Plano Nacional de Educação (PNE) (Brasil, 2014); Base Nacional Comum Curricular (BNCC) (Brasil, 2017); como também, as Diretrizes Curriculares, Parâmetros Curriculares, além de outros. Entende-se assim, que "a educação básica é um conceito mais do que inovador para um país que, por séculos, negou, de modo elitista e seletivo, a seus cidadãos, o direito ao conhecimento pela ação sistemática da organização escolar" (Cury, 2008, p. 294).

Nesse raciocínio, os estudantes se apropriam do direito à educação de qualidade, e os profissionais da sistematização de um currículo que contemple os anseios dessa clientela. Para tanto, o Documento Curricular do Tocantins (DCT) para a Educação Infantil e o Ensino Fundamental, foi criado para aprimorar e orientar o processo de ensino e aprendizagem, nas redes de ensino do território tocantinense. Sendo este um ponto fundamental e o que faz diferença no trabalho do professor para alcançar com êxito o propósito da educação de qualidade e com maiores índices de aprovação. No Tocantins, o DCT do Ensino Médio está em fase final de estudo.

Por isso, essa reflexão sobre a atuação do supervisor pedagógico, poderá contribuir para o entendimento de sua identidade e relevância social, política e administrativa de seu papel na escola quanto ao apoio à prática dos professores, no tocante ao ensino e à aprendizagem. Conforme Pereira (2019, p. 57), o diálogo é fundamental entre supervisão e professor, pois quando ambos expõem "seus pensamentos sobre a educação, suas práticas e demandas, é onde a educação se renova, pois são seus pares colocando no centro de discussão todos os conhecimentos, as experiências, as vivências e as novas propostas nesse ato reflexivo". 


\section{Metodologia}

Trata-se de pesquisa bibliográfica e documental (Mazucato, 2018), que trará a abordagem teórica sobre o tema em dois momentos: o Supervisor Pedagógico e o docente: uma "ponte" para grandes conquistas; e, o Documento Curricular do Tocantins: ações do supervisor pedagógico para possibilitar sua aplicabilidade no ensino e na aprendizagem.

Além disso, quanto aos objetivos foi utilizada a pesquisa exploratória, uma vez que segundo Fontana (2018, p. 60) "buscam estabelecer informações preliminares sobre um dado assunto estudado".

Ainda no artigo científico foi utilizado o método dedutivo, o qual segundo Mazucato (2018, p. 55), "indica que a pesquisa seguirá o seguinte trajeto: partindo de constatações mais gerais (dados, informações, relações já existentes e conhecidas), examinam- se casos particulares para verificar se o mesmo se enquadra nestas constatações mais gerais”.

Sobre a abordagem, foi utilizada a qualitativa, visto que não se utiliza dados estatísticos para análise, no entanto, busca "levar em consideração todos os componentes de uma situação e suas interações e influências recíprocas considerando uma visão/perspectiva holística" (Fontana, 2018, p. 60).

\section{Resultados e Discursões}

\subsection{O Supervisor Pedagógico e o docente: uma "ponte" para grandes conquistas}

Inicialmente é importante destacar que conforme Pavan e Beccari (2014, p. 2) "a Supervisão Educacional era concebida como uma função supervisora não planejada que, com o passar do tempo foi se configurando a partir das exigências estabelecidas pelo contexto educacional".

Com a redemocratização do país, a partir dos anos 90, cresce a necessidade de a figura do supervisor pedagógico na escola assumir sua função técnica e ao mesmo tempo política, para efetivar uma prática que atenda aos anseios populares; e não somente técnica, a serviço da elite. Para tanto, a LDB estabelece uma mudança na legislação, em seu Art. 64:

A formação de profissionais de educação para administração, planejamento, inspeção, supervisão e orientação educacional para a educação básica, será feita em cursos de graduação em pedagogia ou em nível de pós-graduação, a critério da instituição de ensino, garantida, nesta formação, a base comum nacional ((Brasil, 1996).

Nesse contexto, a formação de profissionais de educação para supervisão com atuação na educação básica, passa a ser garantida por lei. Desse modo, sua prática deve atender às novas exigências de uma sociedade que está em constante desenvolvimento e requer do espaço escolar e seus profissionais um trabalho de qualidade.

Libâneo (2002, p. 35) se refere ao supervisor como "um agente de mudanças, facilitador, mediador, interlocutor". Esse profissional na visão do autor é um articulador entre a equipe diretiva, docentes, estudantes e toda a comunidade escolar para o desenvolvimento individual, social, político e também econômico, sem perder de vista o foco que é educar para a cidadania e ética. O que se resume na figura de um profissional comprometido com a formação integral do educando.

Pensar a respeito da mediação do supervisor pedagógico no trabalho docente, é pensar em uma atuação que deve constituir-se como "ponte" para a conquista de grandes desafios, que segundo Bruno; Fortunato e Mesquida (2011, p. 3972): é o resultado da "profissionalização, melhores condições de trabalho e uma prática docente mais crítica, ativa, interventiva e o estudante como um aprendiz competente".

Além disso, é importante alcançar um ambiente educativo democrático e para isso, segundo Leonarde et al. (2019, p. 3):

[...] as leis que regem a educação nacional, instituíram o Projeto Político Pedagógico (PPP) como ferramenta de construção de políticas sociais nas escolas. Isso porque, o PPP define a identidade da escola e organiza o 
trabalho escolar, partindo da elaboração de metas comuns e da revisão do fazer educativo, na busca de solucionar problemas e de elevar a qualidade educacional, num contexto de transformações positivas para a comunidade.

Ainda conforme Bruno; Fortunato e Mesquida (2011), o processo do planejamento escolar revela que a atuação desse profissional é fundamental para a promoção da qualidade do ensino, uma vez que devem conhecer as diversas dinâmicas que ocorrem nas salas de aulas, retomar questões (quando necessário), auxiliar na articulação do planejamento ao conteúdo e ao nível de conhecimento dos estudantes. Desse modo, o supervisor pedagógico tem o desafio de desenvolver a formação continuada docente, motivando-o à promoção da pesquisa e da leitura como práticas constantes. “Acreditamos, pois, que, se há o desejo de formar estudantes leitores vorazes, deve-se, primeiramente, despertar este gosto nos professores" (Bruno; Fortunato \& Mesquida, 2011, p. 3972).

Assim, sobre o supervisor se "faz necessário à comunidade escolar conhecer o trabalho do pedagogo na construção de práticas educativas significativas e pontuais para a comunidade escolar" (Prates et a.l, 2019, p. 9).

A atuação do supervisor nesse processo de acompanhamento da prática pedagógica e interação com os estudantes é fundamental, uma vez que o professor necessita, segundo Pereira (2019, p.18) “da adequação das metodologias e das atividades e do conhecimento sobre como utilizar os instrumentos de diagnóstico e avaliativo dos pré-requisitos para cada série". Essa adequação é estabelecida no DCT como documento norteador curricular nessas fases da Educação Básica: Educação Infantil e Ensino Fundamental.

Segundo os autores Bruno; Fortunato e Mesquida (2011, p. 3973), a prática do professor, quando articulada numa relação dialética entre conhecimento e ação, “com o objetivo de conseguir um fim, buscando uma transformação [...] cuja capacidade de mudar o mundo reside na possibilidade de transformar os outros".

Assim, o currículo escolar é um documento que vem organizar o trabalho pedagógico, respeitando os direitos de aprendizagens dos estudantes, como também suas vivências. À luz do pensamento de Pereira (2019), esse formato organizacional se inicia a partir do diálogo que se dá entre a supervisão pedagógica e o professor, tomando por base o que se pensa sobre a educação, suas práticas e demandas. Nesse contexto, “é onde a educação se renova, pois são seus pares colocando no centro de discussão todos os conhecimentos, as experiências, as vivências e as novas propostas nesse ato reflexivo" (Pereira, 2019, p. 57).

\subsection{O Documento Curricular do Tocantins: ações do supervisor pedagógico para possibilitar sua aplicabilidade no ensino e na aprendizagem}

O Documento Curricular do Tocantins (DCT) para a Educação Infantil e o Ensino Fundamental, foi criado para aprimorar e orientar o processo de ensino e aprendizagem, nas redes de ensino do território tocantinense. De forma colaborativa, os 139 municípios se organizaram para:

atender ao disposto no Art. 76 da Resolução CEE-TO/CP No 024/2019, assim como orientar e esclarecer as responsabilidades de cada instância neste contexto de aprimoramento curricular do processo de ensino e aprendizagem, e atende ao que dispõe a Estratégia 3.1 da Meta 3, do Plano Estadual de Educação, LEI № 2.977, de 8 de julho de 2015 (Tocantins, 2020a, p. 5).

Observa-se que o DCT se divide em quatro cadernos destinados às duas primeiras etapas da educação básica: Educação Infantil e Ensino Fundamental:

$\checkmark \quad$ Sendo um caderno da Educação Infantil, organizado em cinco capítulos: 1- Educação infantil como política; 2Diversidade e identidade cultural do Tocantins; 3- Os profissionais e formação docente; 4- Organização do trabalho pedagógico; 5- Os direitos de aprendizagem e as experiências cotidianas. 
$\checkmark \quad$ Os demais cadernos destinam-se ao Ensino Fundamental, estruturados por competências e habilidades e organizados por área de conhecimento: Linguagens; Ciências Humanas e Ensino Religioso; Ciências da Natureza e Matemática (Tocantins, 2020b, p.11).

Para assegurar a finalidade dos currículos escolares, foram consideradas as histórias dos estudantes, as circunstâncias e as realidades locais, como também os aspectos, voltados ao "planejamento e o monitoramento; a comunicação e o engajamento; os processos formativos; o apoio técnico e o fortalecimento da gestão pedagógica” (Tocantins, 2020a, p.5)

Nesse sentido, a escola assume um papel fundamental:

[...] de garantir um ambiente propício, articulado e coerente às demandas pedagógicas com estratégias eficientes que mobilizem e envolvam toda a comunidade escolar, bem como assegurar aos estudantes um currículo ativo, que contemple a realidade local, regional e considerando a perspectiva do direito a aprendizagem nacional, lembrando que para um currículo vivo é essencial considerar os tempos, espaços, práticas pedagógicas e as rotinas escolares (Tocantins, 2020a, p.12).

Ademais, conforme Alves e Barbosa (2020, p. 3) "enquanto espaço destinado aos processos de ensino aprendizagem, existe a necessidade de que a estrutura organizacional e pedagógica da escola seja efetivamente planejada, para que os processos educativos de qualidade de fato tornem-se realidade".

O responsável pelas demandas pedagógicas é o supervisor, que junto à gestão, irá articular com o corpo docente e a comunidade um currículo vivo e essencial que atenda à qualidade do ensino. Conforme Bruno; Fortunato e Mesquida (2011, p. 3974), “pensar a prática não é somente pensar a ação pedagógica. É um processo de aprendizagem sistemático”. Para os autores, na construção desse processo, alguns momentos são de troca, através de reuniões de estudos e de questionamentos críticos da prática educativa; propostas inovadoras de intervenção na ação docente, que apontem ações referentes à avaliação, como também encaminhamentos didáticos metodológicos das disciplinas curriculares.

O ano letivo de 2020, ano de implementação do DCT, foi um ano atípico, devido à pandemia do Covid-19 e pelos

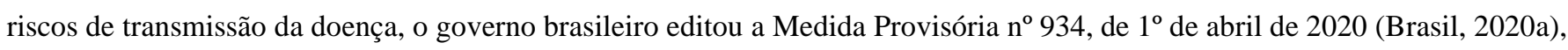
para que as escolas funcionassem no formato à distância. Isso trouxe grandes desafios para todos os profissionais das escolas, e neste estudo, especificamente para o supervisor pedagógico.

Paralelo aos percalços relacionados à falta de recursos humanos, o referido profissional tem as rotinas administrativas atinentes à supervisão escolar, tais como:

a) Buscar atividades que auxiliem os professores em alguma atividade diferenciada que estão dispostos a executar;

b) Atendimento a pais e à comunidade;

c) Controle dos diários de classe, principalmente entre os trimestres, para que não passe despercebido algum dia letivo;

d) Controle dos planejamentos trimestrais e currículo flexibilizados dos alunos de inclusão; controle dos planos avulsos de aula dos professores para possíveis imprevistos;

e) Organização de passeios, sábados integradores, festividades;

f) Elaboração e revisão constante do calendário escolar e projetos vinculados a ele, solicitados periodicamente pela SMED;

g) Orientações trimestrais para os professores como datas de início e término de trimestre, elaboração e correção de pareceres, conselhos diagnósticos, chamados de pais e responsáveis para diálogo com os professores;

h) Acompanhamento, sempre que possível, das aulas, inclusive sempre entrando em sala esporadicamente para dar conta das ausências ou de falta de professores (Pereira, 2019, p. 2).

Essas demandas já fazem parte da rotina da supervisão pedagógica, além de outras funções, como a construção do Projeto Político Pedagógico da escola, Conselhos de Classe. Com a implementação do DCT em 2020, são acrescentadas ao 
supervisor outras incumbências, claro que em colaboração com outros profissionais que integram a equipe pedagógica da escola:

$\checkmark \quad$ Participar ativamente das etapas de formação continuada de implementação do DCT nas modalidades Educação a Distância (EAD) e/ou Presencial;

$\checkmark \quad$ Organizar momentos de estudos com a equipe pedagógica e docente sobre o DCT e as legislações das áreas pertinentes com foco nas metodologias ativas e inserção das tecnologias em sala de aula;

$\checkmark$ Compor, juntamente com o gestor escolar, a coordenação da condução de reestruturação do PPP da unidade escolar, fundamentado no DCT;

$\checkmark$ Acompanhar e orientar o planejamento do professor, com foco nas metas de aprendizagens estabelecidas no PPP e disponibilizar recursos pedagógicos para a sua execução;

$\checkmark \quad$ Monitorar o desempenho acadêmico dos estudantes, a partir dos dados das avaliações internas e externas, tendo como norteador o processo pedagógico de implementação do DCT, a fim de redirecionar o planejamento e as práticas pedagógicas, visando à melhoria dos resultados educacionais;

$\checkmark \quad$ Mobilizar a família e comunidade local, fornecendo-lhes as informações sobre o DCT, para que colaborem no processo de implementação deste currículo;

$\checkmark \quad$ Orientar e possibilitar condições aos docentes e discentes quanto à elaboração de projetos que contribuam com o desenvolvimento local e social da comunidade, propiciando o empreendedorismo, a maturidade e a autonomia do estudante para o alcance das competências e habilidades contidas no DCT;

$\checkmark \quad$ Contribuir para um clima escolar que conduza o professor e o estudante a um ambiente solidário e democrático no processo de ensino e aprendizagem, tornando o DCT um currículo significativo e prazeroso. (Tocantins, 2020a, p.14).

No que se refere às atividades e competências do supervisor pedagógico, as mudanças foram visíveis, pois além de assessorar a prática pedagógica e a formação do professor com o DCT, percebe-se que este profissional precisa estar conectado às inovações, autonomia e protagonismo dos estudantes.

Para tanto, a Base Nacional Comum Curricular (BNCC) destaca metodologias essenciais para um currículo vivo, essencial para a construção do sujeito de forma integral e capaz de construir seu próprio conhecimento (Brasil, 2017). Com isso, o planejamento das aulas dos docentes tem que estar focado nas metodologias ativas e inserção das tecnologias em sala de aula.

De maneira que o currículo, sob uma perspectiva emancipadora necessita ser planejado e articulado com a participação da sociedade, na qual seja valorizado o conhecimento sócio-histórico e cultural para a construção de uma matriz curricular completa para o aluno, ou seja, para o seu desenvolvimento integral e preparo para o exercício da cidadania. (Oliveira, Batista \& Almeida, 2019).

“Criar situações de aprendizagem que favoreçam a atribuição de significado aos conteúdos estudados em sala de aula, de modo que os educandos percebam as relações entre diferentes áreas do conhecimento e a aplicabilidade, destes, em situações do seu cotidiano pode ser visto como um caminho a ser trilhado, mas não como um trabalho trivial" (Brauner, Ferrão \& Santarosa, 2020, p. 14-15).

Para fortalecer o entendimento da organização curricular, os Temas Contemporâneos Transversais (TCTs) na BNCC apontam as diversas possibilidades didático-pedagógicas que integram as diversas formas de organização curricular, conforme três níveis de complexidade: intradisciplinar, interdisciplinar e transdisciplinar:

$\checkmark \quad$ O trabalho intradisciplinar pressupõe a abordagem dos conteúdos relacionados aos temas contemporâneos de forma integrada aos conteúdos de cada componente curricular. Não se trata, portanto, de abordar o tema paralelamente, mas de trazer para os conteúdos e para a metodologia da área a perspectiva dos Temas Contemporâneos Transversais.

$\checkmark \quad$ Por sua vez, a interdisciplinaridade implica um diálogo entre os campos dos saberes, em que cada componente acolhe as contribuições dos outros, ou seja, há uma interação entre eles. Nesse pressuposto, um TCT pode ser trabalhado envolvendo dois ou mais componentes curriculares. 
$\checkmark \quad$ A abordagem transdisciplinar contribui para que o conhecimento construído extrapole o conteúdo escolar, uma vez que favorece a flexibilização das barreiras que possam existir entre as diversas áreas do conhecimento, possibilitando a abertura para a articulação entre elas. Essa abordagem contribui para reduzir a fragmentação do conhecimento ao mesmo tempo em que busca compreender os múltiplos e complexos elementos da realidade que afetam a vida em sociedade (Brasil, 2019, p. 18-19).

Em qualquer uma das formas de abordagem, é fundamental vincular os temas à realidade social para que faça sentido incluir seus conteúdos nos assuntos estudados e para que seja feita sua vinculação com o desenvolvimento das dez competências gerais da BNCC, que, por sua vez, visam à construção da cidadania e formação de atitudes e valores do estudante e da participação ativa da vida em sociedade, e não um fim em si mesmo, conferindo a esses conteúdos um significado maior e classificando-os de fato como Temas Contemporâneos Transversais.

\section{Considerações Finais}

O supervisor pedagógico deve construir um alicerce profissional com clareza política, no sentido de refletir sobre sua ação teórico-prática, relacionada às questões educativas, percebendo, contudo, a cotidianidade que expressa a organização da escola, o seu projeto político pedagógico, a sua filosofia de trabalho, bem como o delineamento das concepções precípuas de sociedade e da educação (Bruno; Fortunato \& Mesquida, 2011, p. 3974).

Outro aspecto fundamental para o sucesso da escola é o clima escolar que viabilize a implementação do DCT de forma participativa e transparente, visando à melhoria dos indicadores educacionais, pautados por ações significativas e lúdicas para os estudantes.

O trabalho pedagógico requer condições favoráveis e espaços para o acompanhamento e planejamento das aulas, cabendo ao gestor escolar, proporcionar essas condições, sem interferências administrativas ou questões internas e externas que comprometam o trabalho da equipe pedagógica na implementação e aplicabilidade do DCT, bem como assegurar a lotação do professor que atenda ao perfil da turma, considerando as transições entre as etapas e suas realidades, bem como respeitando as singularidades dos docentes (Tocantins, 2020a, p.13).

Desse modo, os resultados da investigação apontaram que a implementação do DCT veio assegurar a finalidade dos currículos escolares, considerando as histórias dos estudantes, as circunstâncias e as realidades locais, como também os aspectos, voltados ao planejamento e o monitoramento; a comunicação e o engajamento; os processos formativos; o apoio técnico e o fortalecimento da gestão pedagógica. Isso denota uma nova visão das práticas do Supervisor Pedagógico no espaço escolar, a partir de uma intervenção conceituada na ação coletiva.

Dessa forma, a partir dessa pesquisa, espera-se que trabalhos futuros possam ser direcionados sobre a valorização da supervisão pedagógica, com vistas a interdisciplinaridade e transversalidade na formação dos currículos escolares, o que certamente irá contribuir para uma melhor reflexão sobre a temática e consequentemente, melhorias no ensino-aprendizagem.

\section{Referências}

Alves, S. M. C. \& Barbosa, M. R. B. (2020). Gestão escolar democrática: dimensão diretiva aos processos educacionais significativos. Research, Society and Development, 9(4), e139942985. 10.33448/rsd-v9i4.2985.

Brasil. (1988). Constituição da República Federativa do Brasil de 1988. Planalto Brasília. http://www.planalto.gov.br/ccivil_03/constituicao/constituicao.htm. Brasil. (1996). Lei $\mathrm{n}^{\circ}$ 9394, 20 de dezembro de 1996. Estabelece as diretrizes e bases da educação nacional. http://www.planalto.gov.br/ccivil_03/leis/19394.htm.

Brasil. (2014). Ministério da Educação. Lei no 13.005, de 25 de junho de 2014. Aprova o Plano Nacional de Educação - PNE e dá outras providências. http://www.planalto.gov.br/ccivil_03/_ato2011-2014/2014/lei/113005.htm.

Brasil. (2017). Ministério da Educação. Base Nacional Comum Curricular. Educação é a Base. MEC. http://basenacionalcomum.mec.gov .br/images/BNCC_EI_EF_110518_versaofinal_site.pdf. 
Research, Society and Development, v. 10, n. 12, e589101221073, 2021

(CC BY 4.0) | ISSN 2525-3409 | DOI: http://dx.doi.org/10.33448/rsd-v10i12.21073

Brasil. (2019). Ministério da Educação. Temas Contemporâneos Transversais na BNCC - Contexto Histórico e Pressupostos Pedagógicos. http://www.basenacionalcomum.mec.gov.br/images/implementacao/contextualizacao_temas_contemporaneos.pdf.

Brasil. (2020). Ministério da Saúde. Medida Provisória n ${ }^{\circ} 934$, de 1 de abril de 2020. Estabelece normas excepcionais sobre o ano letivo da educação básica e do ensino superior decorrentes das medidas para enfrentamento da situação de emergência de saúde pública de que trata a Lei $n^{\circ} 13.979$, de 6 de fevereiro de 2020. http://www.in.gov.br/en/web/dou/-/medida-provisoria-n-934-de-1-de-abril-de-2020-250710591.

Brauner, E., Ferrão, N. S., \& Santarosa, M. C. P. (2020). Um estudo das percepções de professores de uma escola pública da região central do Rio Grande do Sul sobre interdisciplinaridade. Research, Society and Development, 9(8), e450985872. https://doi.org/10.33448/rsd-v9i8.5872

Bruno, C. R. C., Fortunato, S. A. de O. \& Mesquida, P. (2011) O Papel do Pedagogo como Mediador no Processo Ensino-Aprendizagem: Trabalho e Crítica. $X$ Congresso Nacional de Educação - EDUCERE. I Seminário Internacional de Representações Sociais, Subjetividade e Educação - SIRSSE. https://educere.bruc.com.br/CD2011/pdf/5655_2867.pdf.

Cury, C. R. J. (2008). A Educação Básica como Direito. Cadernos de Pesquisa, 38(134), 293-303. https://www.scielo.br/j/cp/a/QBBB9Rrm $\mathrm{KBx} 7 \mathrm{MngxzBfWgcF} /$ ?lang=pt\&format=pdf.

Fontana, F. (2018). Técnicas de Pesquisa. In T. Mazucato (Org.), Metodologia da Pesquisa e do Trabalho Científico (pp. 59-80). Ed. Funepe.

Leonarde, G. S. S., de Jesus, T. das G. A., Pinto, T. R. C., \& Silvestre, L. H. A. (2019). Análise dos projetos políticos pedagógicos em escolas da cidade de Teófilo Otoni sob a ótica do planejamento estratégico. Research, Society and Development, 8(1), e2581609. https://doi.org/10.33448/rsd-v8i1.609.

Libâneo, J. C. (2002). Pedagogia e pedagogos: para quê? (6a ed.), Paulo Cortez.

Mazucato, T. (2018). A elaboração do pré-projeto. In T. Mazucato (Org.), Metodologia da Pesquisa e do Trabalho Científico (pp. 40-46). Ed. Funepe.

Oliveira, S. R. de, Batista, S. S. dos S., \& Almeida, I. B. P. de. (2020). Teorias e práticas curriculares na educação profissional e tecnológica. Research, Society and Development, 9(1), e167911807. https://doi.org/10.33448/rsd-v9i1.1807.

Pavan, R. \& Beccari, M. M. B. (2014). Supervisão educacional: uma abordagem a partir das produções acadêmicas. Evento: X Anped Sul, Florianópolis http://xanpedsul.faed.udesc.br/arq_pdf/378-0.pdf.

Pereira, A. C. A. (2019). A supervisão escolar em um contexto de empresariamento da e na educação. http://www.repositorio.jesuita.org.br/bitstream/ handle/UNISINOS/9019/Angelita\%20Carla\%20Alves\%20Pereira_.pdf?sequence=1\&isAllowed=y.

Prates, A. E., Monteiro, A. de O., Rocha, P. C. da S. \& Wanzeler, G. O. R. (2019). O trabalho do supervisor no ensino integrado: o caso de Minas Gerais. Research, Society and Development. 8(10), e198101350 DOI: 10.33448/rsd-v8110.1350.

Tocantins. (2020a). Guia de implementação do documento curricular do Tocantins, educação infantil e ensino fundamental. https://central3.to.gov.br/arquivo/478048/.

Tocantins. (2020b). Documento curricular do Tocantins. Ensino fundamental. Ciências humanas e ensino religioso. https://central3.to.gov.br/arquivo/478053/. 